\title{
INVESTIGATION OF ABSORBENT, ANTIOXIDANT AND THICKENING AGENT PROPERTIES OF TROPICAL FRUIT PEELS
}

\author{
ZALILAH MURNI YUNUS*1, SALIZA ASMAN ${ }^{2}$ AND NURUL ADILA MOHD ALI ${ }^{3}$
}

${ }^{1}$ Advanced Analytical and Environmental Chemistry (AdEC), Department of Physics and Chemistry, Faculty of Applied Sciences and Technology, Universiti Tun Hussein Onn Malaysia, Pagoh Campus, 86400 Pagoh, Muar, Johor, Malaysia. ${ }^{2}$ Department of Physics and Chemistry, Faculty of Applied Sciences and Technology, Universiti Tun Hussein Onn Malaysia, Pagoh Campus, 86400 Pagoh, Muar, Johor, Malaysia. ${ }^{3}$ Department of Technology and Natural resources, Faculty of Applied Sciences and Technology, Universiti Tun Hussein Onn Malaysia, Education Hub Pagoh, 864000, Muar, Johor, Malaysia.

*Corresponding author: zalilah@uthm.edu.my

Submitted final draft: 3 July $2020 \quad$ Accepted: 5 July $2020 \quad$ http://doi.org/10.46754/jssm.2020.12.006

\begin{abstract}
Unripe and ripe of banana, pineapple and mango peel criteria were studied to add information on the use of the peels. A promising adsorbent performance of fruit peels is shown by surface irregularity and morphology. The FTIR result indicated the existence of hemicellulose, cellulose, pectin, and lignin-containing compounds in the peels. Antioxidant properties of mango peel have been proved by the highest TPC (5.50 to 5.90 mg of GAE. ${ }^{-1}$ DW), TFC (26.80 to 37.60 mg of rutin. $\left.\mathrm{g}^{-1} \mathrm{DW}\right)$, DPPH (81.07 to $89.83 \%$ ) and FRAP activity assay (675.07 to $\left.692.07 \mathrm{mmol} \mathrm{FeSO}_{4} \cdot \mathrm{g}^{-1} \mathrm{DW}\right)$ indicates the enrichment of polyphenolic compounds. The equivalent weight of pectin was higher for banana peel (920.73 to $955.65 \mathrm{~g} / \mathrm{mL}$ ), describing a thickening agent. The degree of esterification $(61.75$ to $64.33 \%$ ) showed that the peels can be used for commercial exploitation. The $\mathrm{MeO}$ content for banana peels was 5.44 to $5.85 \%$ and pineapple peels was at 5.85 to $6.67 \%$ and for mango peels it was 8.44 to $9.01 \%$. The AUA content revealed that banana (49.99 to $51.63 \%$ ) and pineapple (55.73 to $58.53 \%$ ) peels have low purity of pectin meanwhile mango peels showed a higher ( 68.17 to $72.28 \%$ ) pectin quality. To summarise, those fruit peels have potential characteristic as an adsorbent, antioxidant and thickening agent.
\end{abstract}

Abbreviations: TPC: Total Phenolic Content; TFC: Total Flavonoid Content; DPPH: Ability of 2, 2 - diphenyl - 1 - picrylhydrazyl; FRAP: Ability of Ferric Reducing Antioxidant Potential Assay; RBP: Ripe Banana Peel; UBP: Unripe Banana Peel; RMP: Ripe Mango Peel; UMP: Unripe Mango Peel.

\section{Introduction}

Malaysia is one of the tropical countries that plant many types of fruit. Some fruits are indigenous and others brought from elsewhere to this country and planted with high potential and possibilities for commercial development. According to statistics from the Department of Agriculture (2016), there is a high demand for fruits imported from overseas which was around 807,185 metric tons (mt) in 2015. Then in 2016, the areas for fruit plantation increased with 194,970 hectares (ha) for 1,621,813 mt of fruit production (DOA, 2016). Consequently, a large number of by-products of fruits are available in abundance, caused by the high demand for fruit products from fruit processing industry (Sommano(a), 2018); Sommano(b), 2018). These by-products are known as "fruit and vegetable waste (FVW)" that includes leaf, pulp, stems, bark and peels (Plazzotta et al., 2017).

The peel is fruit by-product that builds up from particular parenchyma cells which consist of a cellulose layer that gives a protective, rigid tissues and thickens the cell wall of the entire fruit and is not consumed but commonly discarded as waste (Anwar et al., 2010). This waste can cause some environmental nuisance and emit bad odour to the environment as a growth medium for microorganisms however, the reuse of fruit waste will be able to benefit the cost of solid-waste handling. It is a wellknown fact that fruits that produce peel wastes are generally bananas, mangoes and pineapples with about 7.0 to $34.7 \%$ from the total weight of fruit (Ibrahim et al., 2017; Jahurul et al., 2015). 
Banana (Musa acuminate) belongs to the family of Musaceae. The average weight of the banana fruit is $25 \%$ dry matter, $75 \%$ water and $30 \%$ peel waste (Ibrahim et al., 2016). Mangoes (Mangifera indica L.) belong to the family of Anacardiaceae. About $35-60 \%$ of peel and seed waste from the total weight of fruit, and about $7-24 \%$ of the total weight of the fruit comes from processing the mango (Jahurul et al., 2015). Pineapples (Ananas comosus Merr) are about $50 \%(\mathrm{w} / \mathrm{w})$ peel and stem waste from the total weight of the fruit (Dai et al., 2016) and about $34.7 \%$ of the whole mass of fruits is accounted for the peel waste (Pandit et al., 2015).

In order to overcome the environmental issue and reduce the cost of fruit waste handling, it is crucial to investigate the potential of fruit peels for their different applications as a primary study to produce value-added products. There had been similar investigations on fruit peels (Njoku et al., 2014; Hossain et al., 2012; Dotto et al., 2016), however the characteristics and potential of unripe and ripe peel waste has not yet documented. Taking into consideration that the peel waste is rich with lignocellulosic compounds such as lignin and hemicellulose, this study will therefore investigate the physicochemical characteristics of banana, pineapple and mango peels, focusing on their ripeness.

This study demonstrated the highest carbohydrate contents, and phenolic compounds or antioxidant activity of unripe peels and ripe peels of banana, pineapple and mango, thus justifying future actions in the expansion of planting and consumption of these fruit (Aquino et al., 2015).

The aim of this study was to observe the preparation and evaluation of the characterization of physicochemical properties of banana, pineapple, and mango peels. The study on the physical properties comprised surface morphology analysis, proximate analysis, and bulk density. The study on the chemical properties encompassed the determination of chemical functional group, surface $\mathrm{pH}$, antioxidant activity and pectin analysis. Using the obtained experimental results, the physicochemical properties of a ripe banana peel (RBP), unripe banana (UBP), ripe mango (RMP), unripe mango (UMP), ripe pineapple (RPP) and unripe pineapple (UPP) peels were compared in terms of their suitability as adsorbent, antioxidant and thickening agents. It is believed that this work can deliver useful information about the physicochemical properties of those fruit peels for more potential uses and will deliver useful information on the physicochemical criteria of the unripe and ripe fruit peels for further investigation on potential uses. Consequently, a future study on the potential use of this biomass waste can be proposed for further establishment.

\section{Materials and Methods}

\section{Reagents}

The chemicals used in this study are ethanol (EtOH, $96 \%$ ), sulfuric acid $\left(\mathrm{H}_{2} \mathrm{SO}_{4}, 98 \%\right)$ and nitric acid $\left(\mathrm{HNO}_{3}, 65 \%\right)$ and were supplied from $\mathrm{HmBg}$, Germany. Methanol (MeOH, 85 $\%)$ and sodium carbonate $\left(\mathrm{Na}_{2} \mathrm{SO}_{3}, 2 \%\right)$ were supplied from Bendosen, Malaysia. FolinCiocalteu reagent, gallic acid, aluminium chloride $\left(\mathrm{AlCl}_{3}, 10 \%\right)$, potassium carbonate $\left(\mathrm{K}_{2} \mathrm{CO}_{3}\right)$, rutin solution, tripyridyltriazine (TPTZ) solution, iron chloride $\left(\mathrm{FeCl}_{3}\right)$ and 2,2-diphenyl-1-picrylhydrazyl (DPPH) were bought from Sigma-Aldrich, Malaysia. The methanolic solution, sodium acetate buffer solution $\left(\mathrm{CH}_{3} \mathrm{COONa}, 300 \mathrm{mmol}\right)$, sodium hydroxide $(\mathrm{NaOH})$, phenol red, potassium acetate $\left(\mathrm{C}_{2} \mathrm{H}_{3} \mathrm{KO}_{2}\right)$, hydrochloric acid $(\mathrm{HCl})$ and sodium chloride $(\mathrm{NaCl})$, were purchased from QRec, Malaysia. All chemicals are the grade for analytical research.

\section{Instrumentation}

The instruments used were 7600F FieldEmission Scanning Electron Microscope (FESEM) (JEOL, Czech Republic), Fourier Transform Infrared Spectroscopy (Perkin Elmer Spectrum 100, USA), T60 UV-Vis Spectrophotometer (PG instruments, UK), 
hot air oven (Memmert, Germany), grinder (Waring Commercial, USA), muffle furnace (The Carbolite ELF 11/14B, United Kingdom), Sieve Shaker (Retsh-Alle-1-5 42781, Germany), Velp Scientifica Heated Circulating Bath (Italy), Rotatory Evaporator (RE301, China) and $\mathrm{pH}$ meter (Eutech Instruments, USA).

\section{Sample Preparation}

The three types of unripe and ripe tropical fruit peels, UBP, RBP, UPP, RPP, UMP, and RMP were collected from a fruit stall. Classification of their ripening level was done by observing the colour of the peels. Green peel indicates the unripe peel whereas yellow peel indicates ripe peel. The preparation of tropical fruit peels was adopted with minor modifications from Afsharnezhad et al. (2017) and Abang Zaidel et al. (2015). The fruit peels were washed with distilled water to eliminate any external dirt or physical impurities. Then, the fruit peels were aired in a hot air oven for $24-30$ hours to achieve a constant weight. In this work, two different temperatures were conducted due to different analyses, the antioxidant analysis and the physical adsorbent properties and thickening analysis where the fruit peels were aired at $40^{\circ} \mathrm{C}$ and at $65{ }^{\circ} \mathrm{C}$ respectively. Later, the fruit peels were ground and sieved with $125-250 \mu \mathrm{m}$ mesh sieve, and the sample powders were kept in polyethylene bag for further studies.

\section{Phenol Extraction}

$200 \mathrm{~g}$ of fine powder of the fruit peels was extracted twice by using Soxhlet extraction method and $200 \mathrm{~mL}$ of $85 \% \mathrm{MeOH}$ at ambient temperature for two days. Then, the filtrate was pooled, concentrated and rotary-evaporated at temperature $40{ }^{\circ} \mathrm{C}$. The extracts obtained were kept in a desiccator for further analysis (Afsharnezhad et al., 2017).

\section{Pectin Extraction}

Pectin extraction was conducted using a conventional extraction method which is based on the acid-catalysed process. The fruit peels were immersed in distilled water with the solid-liquid ratio of 1:9 (w/v, \%). Then, $1 \mathrm{M}$ of
$\mathrm{H}_{2} \mathrm{SO}_{4}$ was added for $\mathrm{pH}$ adjustment to $\mathrm{pH} 2$. The immersion was circulated by using heated circulating bath for 15 mins and further heated in a water bath at $82{ }^{\circ} \mathrm{C}$ for 105 mins. After the heating process, the hot acid (filtrate) was extracted and filtered by using a muslin cloth. The filtrate was coagulated by mixing $96 \%$ $\mathrm{EtOH}$ and kept for $30 \mathrm{hrs}$ in ambient temperature to acquire the pectin float on the surface. Later, the floated pectin was skimmed off by filtering and washing step with $70 \% \mathrm{MeOH}$. Finally, the resulting pectin was aired overnight at $35^{\circ} \mathrm{C}$ in a hot air oven (Girma \& Worku, 2016; CastilloIsrael, 2015).

\section{Evaluation of Surface Morphology of the Peel}

Surface morphology was characterised by Field Emission Scanning Electron Microscope (FESEM) (JSM-7600F). The observation of surface morphology was conducted for a sample of untreated and treated fruit peels. The surface morphology was determined at 1000x magnifications at working voltage $5.0 \mathrm{kV}$.

\section{Determination of Proximate Analysis of the Peel}

Proximate analysis provides valuable information about the nutritional composition and helps to access the quality of the sample and it included moisture content, volatile matter, ash content, and bulk density. The volatile matter experiment was conducted according to method carried out by Pathak et al. (2016), where the aired fruit peel samples were heated at $900{ }^{\circ} \mathrm{C}$ for 7 mins in the muffle furnace. Then, the samples were aired and kept in a desiccator. For volatile matter measurement, the samples were weighed before and after heating, then calculated the weight loss of samples using Equation [1]. For ash content measurement, the samples were aired at $500{ }^{\circ} \mathrm{C}$ for $30 \mathrm{mins}$ in a muffle furnace. The samples then were heated at 815 ${ }^{\circ} \mathrm{C}$ until constant weight was reached and kept in a desiccator at ambient temperature. The ash content of samples was determined by Equation [2]. For the bulk density experiment, the method used was adopted from Yoshiyuki and Yukata 
(2003), where $10 \mathrm{~cm}^{3}$ dried measuring cylinder was cleaned, aired and weighed. Then, $10 \mathrm{~g}$ of dried fruit peels were filled into the measuring cylinder which was tapped gently until the volume of the sample inside it stopped to decrease. Then, the bulk density was calculated using Equation [3]. The moisture content was evaluated where $5 \mathrm{~g}$ of dried fruit peel samples were heated in a hot air oven at $120^{\circ} \mathrm{C}$ until the samples reached constant weight. Then, the percentage of moisture was determined by Equation [4] (Pathak et al.,2016).

$$
\begin{aligned}
& \text { Volatile matter }(\%)=\frac{\text { Loss in weight due to removal volatile matter }(\mathrm{g})}{\text { Weight of sample }(\mathrm{g})} \times 100 \\
& \text { Ash }(\%)=\frac{\text { Weight of ash left after heating }(\mathrm{g})}{\text { Weight of sample }(\mathrm{g})} \times 100 \\
& \text { Bulk density }\left(\mathrm{g} / \mathrm{cm}^{3}\right)=\frac{\text { Weight of sample }(\mathrm{g})}{\text { Volume of sample }\left(\mathrm{cm}^{3}\right)} \\
& \text { Moisture }(\%)=\frac{\text { (Weight of sample }(\mathrm{g}) \text {-Weight after drying }(\mathrm{g})}{\text { Weight of sample }(\mathrm{g})} \times 100
\end{aligned}
$$

\section{Determination of the Chemical Functional Group of the Peel}

\section{Determination of Total Flavonoid Content (TFC)}

The chemical functional group of samples was characterised by using Fourier Transform Infrared Spectroscopy (Perkin Elmer Spectrum 100 ) at wavelength range of 3500 to $700 \mathrm{~cm}^{-1}$.

\section{Determination of Surface $\mathrm{pH}$ of the Peel}

A sample dried fruit peels $(1 \mathrm{~g})$ was poured with double-distilled water $(50 \mathrm{~mL})$, and shaken well by using a heated circulating bath at $30^{\circ} \mathrm{C}$ overnight. Then, the mixture was filtered and the final $\mathrm{pH}$ was measured which gives the surface $\mathrm{pH}$.

\section{Determination of total Phenolic Content (TPC) of Phenolic Extract}

The phenolic extractant $(100 \mu \mathrm{L})$ was mixed with Folin-Ciocalteu reagent $(100 \mu \mathrm{L}), 2 \% \mathrm{Na}_{2} \mathrm{CO}_{3}$ $(2 \mathrm{~mL})$ and deionized water $(3.8 \mathrm{~mL})$. The solution was incubated for $30 \mathrm{mins}$ at ambient temperature. The result obtained was expressed as $\mathrm{mg}$ gallic acid equivalents (GAE). $\mathrm{g}^{-1} \mathrm{DW}$. The absorbance value was determined by using UV-Vis spectrophotometer at a wavelength of $720 \mathrm{~nm}$ (Meda et al., 2005).
The extracted sample $(500 \mu \mathrm{L})$ was added with $85 \% \mathrm{MeOH}(1.5 \mathrm{~mL}), 10 \%$ aluminum chloride methanolic solution $(100 \mu \mathrm{L}), 1 \mathrm{M}$ $\mathrm{C}_{2} \mathrm{H}_{3} \mathrm{KO}_{2}$ solution $(100 \mu \mathrm{L})$ and distilled water $(2.8 \mathrm{~mL})$. The mixture was incubated for 40 mins at ambient temperature. The absorbance was measured at $415 \mathrm{~nm}$ by using UV-Vis spectrophotometer. The result obtained was expressed in $\mathrm{mg}$ rutin $\mathrm{g}^{-1} \mathrm{DW}$ (Afsharnezhad et al., 2017).

\section{Ability of 2, 2 - Diphenyl - 1 - Picrylhydrazyl (DPPH) Radical Scavenging Activity}

$0.004 \% \quad 2,2$ - diphenyl-1-picrylhydrazyl (DPPH) methanolic solution $(2 \mathrm{~mL})$ was added to the extract solution $(2 \mathrm{~mL})$. Whilst, DPPH (2 $\mathrm{mL})$ was mixed to $\mathrm{MeOH}(2 \mathrm{~mL})$ as a control. Then, the mixture was kept in the dark for 30 mins. The absorbance of the mixture was measured by using UV-Vis spectrophotometer at $501 \mathrm{~nm}$ with the $\mathrm{MeOH}$ blank without DPPH. The inhibition rate (\%) of the DPPH radical was calculated (Afsharnezhad et al., 2017). 
Ability of Ferric Reducing Antioxidant Potential Assay (FRAP)

In using the adopted procedure from Afsharnezhad et al. (2017), fruit peel extracts $(0.05 \mathrm{~mL})$ were mixed with distilled water. At ambient temperature, FRAP reagent $(1.5 \mathrm{~mL})$ was poured into the mixture and incubated for 30 mins. The mixture of distilled water $(0.05$ $\mathrm{mL})$ with FRAP reagent $(1.5 \mathrm{~mL})$ was prepared as a control. The Ferric reducing antioxidant activity (FRAP) solution was prepared with a proportion of 10:1:1 (v:v:v) of $\mathrm{L}^{-1} \mathrm{CH}_{3} \mathrm{COONa}$ buffer solution (300 mmol, $\mathrm{pH}$ 3.6), TPTZ solution $\left(10 \mathrm{mmol} \mathrm{L}^{-1}\right.$ in $\left.40 \mathrm{mmol} \mathrm{L}-1 \mathrm{HCl}\right)$ and $\mathrm{FeCl}_{3}$ solution $\left(20 \mathrm{mmol} \mathrm{L}^{-1}\right)$. The absorbance was measured at wavelength $593 \mathrm{~nm}$ by using
UV-Vis spectrophotometer. The antioxidant capacity was determined by expressing in $\mu \mathrm{mol}$ of iron sulfate $\left(\mathrm{FeSO}_{4} \cdot \mathrm{g}^{-1} \mathrm{DW}\right)$.

\section{Determination of Equivalent Weight}

Pectin substances $(0.5 \mathrm{~g})$ were balanced and diluted with $\mathrm{EtOH}(5 \mathrm{~mL})$ and mixed with $\mathrm{NaCl}$ $(1 \mathrm{~g})$. Subsequently, distilled water $(100 \mathrm{~mL})$ was added with six drops of phenol red. Then, the solution was titrated gradually with 0.1 $\mathrm{N} \mathrm{NaOH}$ until the pink colour appeared. The neutralised solution was utilised to identify the methoxyl content. The equivalent weight of pectin extraction was calculated using Equation [5] (Rose \& Abilasha, 2016; Girma \& Worku, 2016).

$$
\text { Equivalent weight }=\frac{\text { weight of the sample }(\mathrm{g})}{\mathrm{mL} \text { of alkali } \times \text { Normality of alkali }} \times 1000
$$

Determination of Degree of Esterification (DE)

The degree of esterification (DE) is well-defined as the ratio of esterified galacturonic acid groups to the galacturonic acid groups present (Shan Qin et al., 2014). The DE was calculated using Equation [6] (Girma \& Worku, 2016).

$$
\text { Degree of esterification }(\mathrm{DE})=\frac{176 \times \text { methoxyl content }(\mathrm{MeO})(\%) \times 100}{31 \times \mathrm{AUA}(\%)}
$$

\section{Determination of Methoxyl Content (MeO)}

$0.25 \mathrm{~N} \mathrm{NaOH}(25 \mathrm{~mL})$ was added with the neutralised solution prepared from the equivalent weight. At ambient temperature, the solution was mixed and made to stand for 30 mins. Later, $0.25 \mathrm{~N} \mathrm{HCl}(25 \mathrm{~mL})$ was added and titrated with $0.1 \mathrm{~N} \mathrm{NaOH}$ until the colour of the indicator changed to pink. The percentage of $\mathrm{MeO}$ was calculated using Equation [7] (Rose \& Abilasha, 2016; Girma \& Worku, 2016).

$$
\mathrm{MeO}(\%)=\frac{\mathrm{mL} \text { of alkaline }(\mathrm{NaOH}) \times \mathrm{N} \text { alkaline }(\mathrm{NaOH}) \times 3.1}{\text { weight of sample }(\mathrm{g})}
$$

\section{Determination of Total Anhydrouronic Acid (TAUA)}

The total anhydrouronic acid (TAUA) was calculated using the value measured from equivalent weight and methoxyl content and was calculated by Equation [8] (Girma \& Worku, 2016).

$$
\mathrm{TAUA}=\frac{176 \times 0.1 z \times 100}{\mathrm{~W} \times 1000}+\frac{176 \times 0.1 y \times 100}{\mathrm{~W} \times 1000}
$$

$z=\mathrm{mL}$ of $\mathrm{NaOH}$ from equivalent weight determination

$y=\mathrm{mL}$ of $\mathrm{NaOH}$ from methoxyl content determination 


\section{Statistical Analysis}

All the physical and chemical analyses were conducted in triplicate. The data was reported in mean \pm standard deviation (SD).

\section{Results and Discussion}

Figure 1 shows the surface morphology of fruit peel samples. The untreated UBP, UPP, and UMP have a rough and non-porous structure.

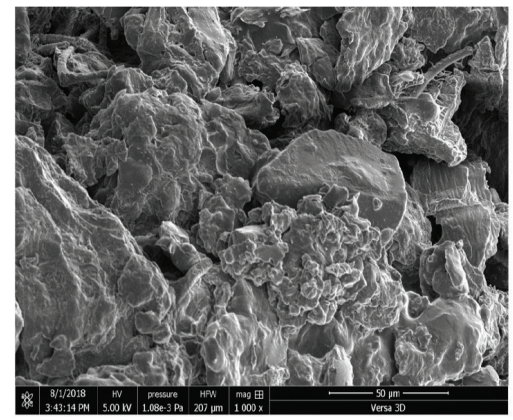

(a) Untreated RBP

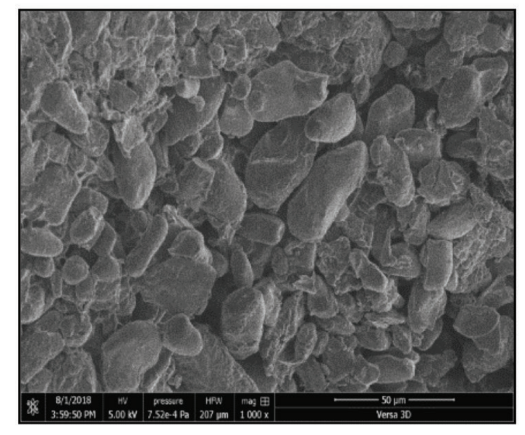

(c) Untreated UBP

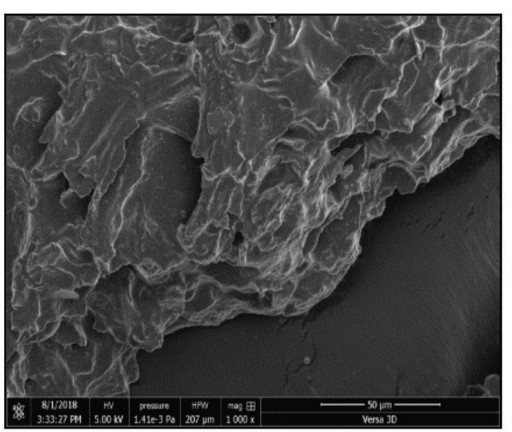

(e) Untreated RPP
Nonetheless, the untreated of RBP, RPP and RMP indicate the naturally rough, irregular and porous structure. The porosity structure of pretreatment and post-treatment of UBP and RBP show a larger size than UPP, RPP, UMP, and RMP. The banana peel has a rough and irregular surface surrounded with crater-like pores, thus has potential to provide metal-surface interaction and bio-sorption process (Pathak et al., 2017; Alaa El-Din et al., 2018)

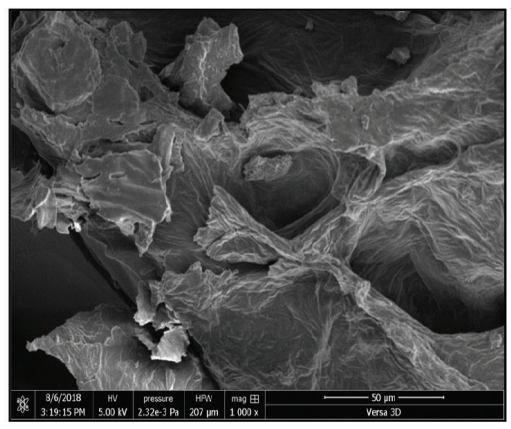

(b) Treated RBP

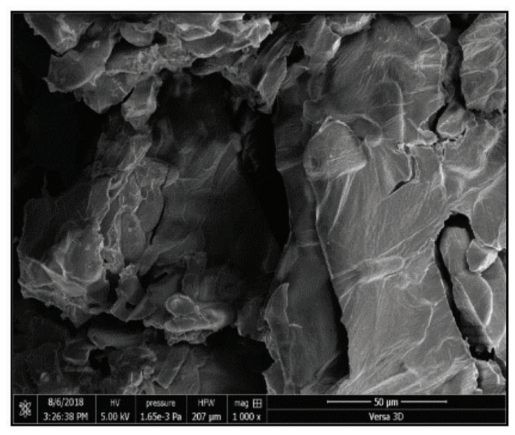

(d) Treated UBP

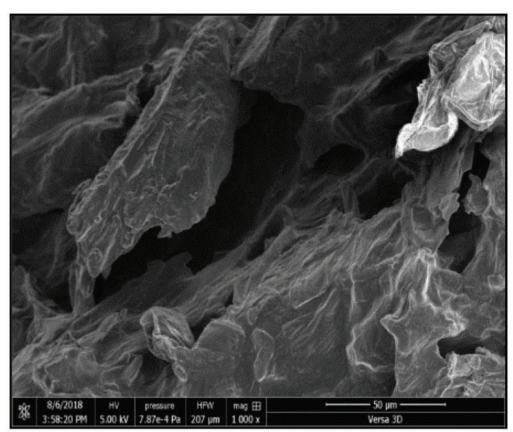

(f) Treated RPP 


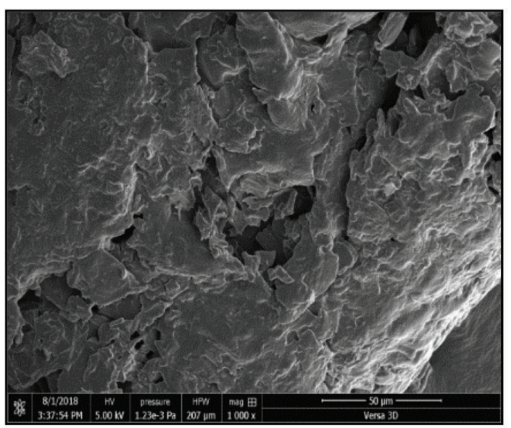

(g) Untreated UPP

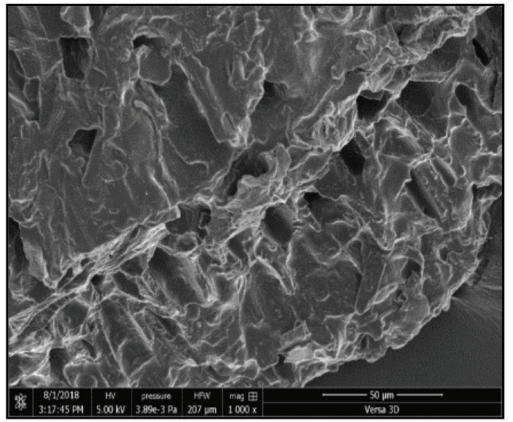

(i) Untreated RMP

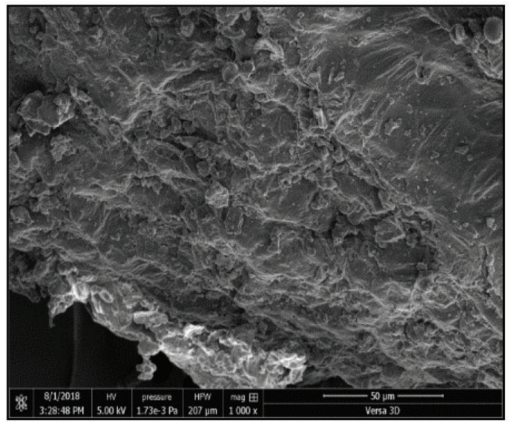

(k) Untreated UMP

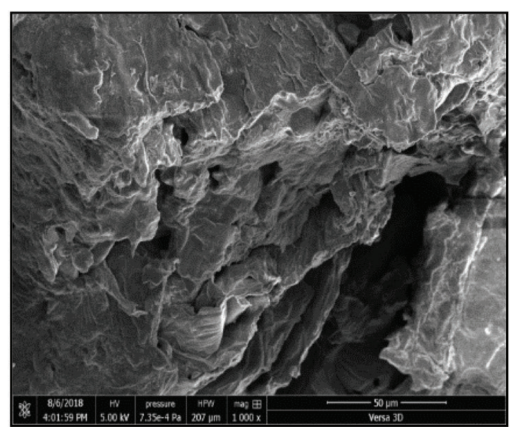

(h) Treated UPP

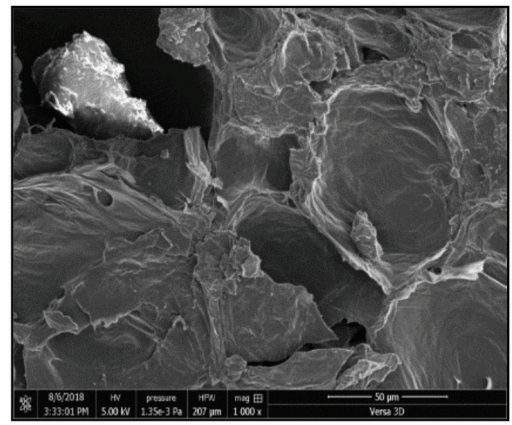

(j) Treated RMP

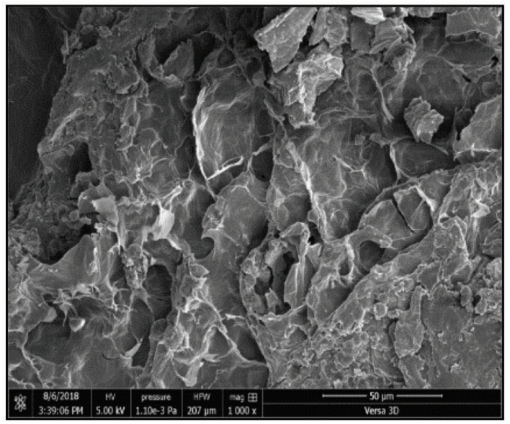

(1) Treated UMP

Figure 1: Surface morphology of treated and untreated fruit peels (1000 x magnification, $5.0 \mathrm{kV})$

Pore diameters of RBP, UBP, RPP, UPP, $\mathrm{RMP}$, and UMP were compared between pretreatment and post-treatment. Since treated fruit peels exposed large pores, the calculation can be made to discover the diameter of the pores. The diameters of BP (R) and B (UR) are 4.35 \pm 1.55 and $4.67 \pm 0.64 \mu \mathrm{m}$ respectively. The diameter of pores for MP (R) was bigger than MP (UR) that is, $5.94 \pm 2.26$ and $1.69 \pm 0.58$ $\mu \mathrm{m}$ respectively. For the peel of $\mathrm{PP}(\mathrm{R})$ and $\mathrm{PP}$ (UR), the diameters are $2.50 \pm 0.36 \mu \mathrm{m}$ and 1.51 \pm 0.18 respectively. Thus, it can be presumed that there is a potential of effective adsorbent that can be employed from peels of BP (R), BP (UR) and MP (R).

The result also indicates that the structure of all fruit peels has irregular shape and pores after treatment process was carried out. However, the 
pores of treated RBP, RPP and RMP are larger than treated UPP, RPP, UMP, and RMP. It can be described that the treatment with acid produces a superior pore structure with large diameter and volume size, thus providing and improving the effectiveness of high adsorption capacity (Orozco et al., 2014; Jawad et al., 2016). Convince that, RBP, UBP, RPP, UPP, RMP, and UMP can be possible as adsorbent material as their structure is heterogeneous of pores after treating with acid.

\section{Determination of Surface pH}

The surface $\mathrm{pH}$ of RBP, UBP, RPP, UPP, RMP, and UMP was found in the range of $3.13-6.04$ (Table 1).

It was observed that UPP, RPP, UMP, and RMP are in the range of acidic $\mathrm{pH}(3.13-4.77)$. The $\mathrm{pH}$ value of ripe fruit peels is higher than that of the unripe ones and this may have been the effect of ripening on the fruit. However, the $\mathrm{pH}$ of banana peel decreased during ripening from 6.04 (UBP) to 5.53(RBP). The result agrees with a study by Pathak et al. (2016) but slightly different in value due to a different cultivar of banana peel used. The $\mathrm{pH}$ of UBP and RBP was closer to neutral, thus it can use for adsorption of both anions and cations contaminants (Pathak et al., 2017). As these fruits matured (unripe to ripe), the acidity of the fruit decreased due to fewer hydrogen ions. When the hydrogen ions concentration of peel decrease, the $\mathrm{pH}$ value of the peel is increased (Hajar et al., 2012).
The reducing acidity in UPP, RPP, UMP, and RMP could be due to the susceptibility of citric acid to oxidative destruction as a result of the ripening process, caused by the starch hydrolysis leading to increased total sugars, thus reducing acidity and lessening sourness with improving the sweet taste (Devi et al., 2013). It is summarised that the surface $\mathrm{pH}$ of RBP and UBP which is nearly neutral can be used for adsorption of cations and anion contaminants adsorption. The surface $\mathrm{pH}$ of RPP, UPP, RMP, and UMP which is more acidic than basic is favourable for the cationic ions adsorption rather than anionic ions.

\section{Determination of Proximate Analysis}

The results of a proximate analysis on RBP, UBP, RPP, UPP, RM, and UMP are tabulated in Table 2. The moisture content of peels are in the range of $85.06-68.26 \%$, showing that the moisture content of peels is high. Moisture content indicates the shelf-life and freshness of the product, as well as the high moisture content, and is accountable for microbial spoilage, deterioration and short shelf life. From the absorbent properties perspective, high moisture hinders ignition and reduces the combustion temperature. This adversely affects the reaction products of combustion and quality of combustion (Mandavgane et al., 2017). In order to produce successful absorbent, a study on the optimum temperature and time endurance of combustion is vital for determining the level of moisture content.

Table 1: The $\mathrm{pH}$ of raw and dried fruit peels

\begin{tabular}{ccc}
\hline Types of fruit peel & $\mathbf{p H}$ of raw fruit peel $^{\mathbf{s}}$ & $\mathbf{p H ~ o f ~ d r i e d ~ f r u i t ~ p e e l ~}^{\mathbf{b}}$ \\
\hline RBP & $5.84 \pm 0.03$ & $5.53 \pm 0.00$ \\
UBP & $6.04 \pm 0.03$ & $5.94 \pm 0.01$ \\
RPP & $4.77 \pm 0.02$ & $4.08 \pm 0.00$ \\
UPP & $4.60 \pm 0.01$ & $3.80 \pm 0.01$ \\
RMP & $4.11 \pm 0.00$ & $3.92 \pm 0.00$ \\
UMP & $3.90 \pm 0.02$ & $3.13 \pm 0.00$ \\
\hline
\end{tabular}

Note: a represents the study of $\mathrm{pH}$ for ripe and unripe fruit peels; $b$ represents the study of the surface $\mathrm{pH}$ of dried fruit peels. 
Table 2: Proximate analysis of fruit peel

\begin{tabular}{ccccc}
\hline Type of fruit peel & $\begin{array}{c}\text { Moisture } \\
\mathbf{( \% )}\end{array}$ & $\begin{array}{c}\text { Ash } \\
\mathbf{( \% )}\end{array}$ & $\begin{array}{c}\text { Volatile matter } \\
(\mathbf{\%})\end{array}$ & $\begin{array}{c}\text { Bulk density } \\
\mathbf{( g / \mathbf { c m } ^ { 3 } )}\end{array}$ \\
\hline RBP & $82.80 \pm 0.80$ & $2.73 \pm 0.70$ & $12.60 \pm 0.52$ & $0.56 \pm 0.00$ \\
UBP & $82.40 \pm 2.43$ & $2.06 \pm 0.64$ & $14.86 \pm 2.48$ & $0.63 \pm 0.00$ \\
RPP & $84.86 \pm 0.46$ & $0.93 \pm 0.30$ & $14.46 \pm 0.57$ & $0.33 \pm 0.01$ \\
UPP & $85.06 \pm 0.41$ & $0.73 \pm 0.11$ & $12.73 \pm 0.41$ & $0.40 \pm 0.11$ \\
RMP & $68.26 \pm 3.06$ & $2.06 \pm 0.30$ & $24.86 \pm 1.62$ & $0.64 \pm 0.02$ \\
UMP & $76.40 \pm 0.34$ & $0.66 \pm 0.11$ & $18.93 \pm 0.30$ & $0.63 \pm 0.00$ \\
\hline
\end{tabular}

The quality of fruit peel can be measured by ash content and the number of mineral elements analysis. Ash is the inorganic residues or incombustible solid material residual after organic matter and water have been released by heating. The percentage of ash content is low in the range of $0.66-2.73 \%$. These values are in agreement with the value ash in the range of 1 $20 \%$ for the better adsorption as well as better absorbent (Ekpete et al., 2017). Low ash with a maximum limit of $10 \%$ of ash content is a good criterion for gel formation on the sight of thickening agent properties. This is supported by Romelle et al., (2016) who presented that the resulting of ash contents for a banana, pineapple and mango are $12.45 \pm 0.38 \%, 4.39 \pm 0.14 \%$, and $3.24 \pm 0.18 \%$, respectively, determine per $100 \mathrm{~g}$ of the dry peel. Different result values are based on dry weight for three varieties of the fruit peels.

The bulk density (Table 2 ) of the fruit peels is low between $0.33-0.64 \mathrm{~g} / \mathrm{cm}^{3}$. Pathak et al. (2016) and Pathak et al. (2017) found that the bulk density of banana peel is $0.39 \mathrm{~g} / \mathrm{cm}^{3}$ and pineapple peel is $0.52 \mathrm{~g} / \mathrm{cm}^{3}$. The low in bulk density was good for the adsorption process which contributed to the high porosity of fruit peels. As summarised in Table 1, RPP and UPP have a lower bulk density with the higher moisture content compared to other fruit peels. Meanwhile, UMP and RMP showed the highest bulk density and lowest percentage of moisture content. The dissimilarity in bulk density of fruit peels is mainly due to differences in particle shape, particle size of both. The increased porosity can increase the volume of entrapped air. Moreover, the high moisture content of fruit peels due to the high fiber content of peels results in a large number of hydrophilic groups. Nevertheless, the low bulk density makes fruit processing and storage complicated (Mandavgane et al., 2017). The percentage of volatile matter is due to the organic nature of fruit peels such as lipids, proteins, and carbohydrates. Volatile compounds emitted are aldehydes, alcohols, ketones, esters, terpenes and hydrocarbons and hydrocarbon (Rosenkranze \& Schnitzler, 2016).

The results of volatile matter range between $12.60-24.86 \%$. High percentage of volatile matter in RMP and UMP indicates it as having better potential as antioxidant compared to other samples (Chua et al., 2018). The low level of volatile matter resulted in the evaporation of the non-carbon compounds that are volatile at the carbonisation process. It shows that the fruit peels are difficult to ignite and burn, but the combustion is rapid and hard to control. Further, the low volatile matter directed complete combustion. Hence, the release and combustion of volatiles are crucial factors to be considered for combustion systems such as design and operation (Mandavgane et al., 2017). Thus, in order to produce a great absorbent from fruit peel with great efficient adsorption properties, the proximate analysis is the main study and the optimization study for each related parameter should be considered.

\section{Determination of the Chemical Functional Group}

Table 3 summarises the chemical functional groups contained in all fruit peel samples. It 
Table 3: FTIR peaks of fruit peel

\begin{tabular}{ccccccc}
\hline \multirow{2}{*}{\begin{tabular}{c} 
Type of fruit $\begin{array}{c}\text { Obtained peaks } \\
\text { peels }\end{array}$ \\
\cline { 2 - 7 }
\end{tabular}} & $\mathrm{O}-\mathrm{cm}$ & $\begin{array}{c}\mathrm{C}-\mathrm{H} \\
\text { stretching }\end{array}$ & $\mathrm{C}=\mathrm{C}$ & $\begin{array}{c}\mathrm{C}-\mathrm{H} \\
\text { bending }\end{array}$ & $\begin{array}{c}\mathrm{C}-\mathrm{O} \\
\text { bending }\end{array}$ & $\mathrm{C}-\mathrm{OR}$ \\
\hline RBP & 3279.91 & 2966.12 & 1614.97 & 1311.20 & 1232.38 & 999.86 \\
UBP & 3279.01 & 2919.65 & 1601.19 & 1398.68 & 1229.56 & 1031.28 \\
RPP & 3282.18 & 2957.32 & 1634.72 & 1363.44 & 1243.56 & 1032.34 \\
UPP & 3277.12 & 2954.76 & 1623.73 & 1362.34 & 1244.03 & 1032.64 \\
RMP & 3275.25 & 2817.73 & 1610.63 & 1401.22 & 1236.53 & 1033.00 \\
UMP & 3275.32 & 2862.91 & 1629.55 & 1380.82 & 1254.30 & 1033.08 \\
\hline
\end{tabular}

found peaks at $3282.18-3275.25 \mathrm{~cm}^{-1}$ and 1033.08 - $999.86 \mathrm{~cm}^{-1}$ which correspond to $\mathrm{O}-\mathrm{H}$ stretching and $\mathrm{C}-\mathrm{OR}$ and stretching of ester or ether respectively in the samples. The spectra also indicated the presence of $\mathrm{C}-\mathrm{O}$ bending of lignin band $\left(1229.56-1254.30 \mathrm{~cm}^{-}\right.$ $\left.{ }^{1}\right), \mathrm{C}=\mathrm{C}$ aromatic rings $\left(1601.19-1634.72 \mathrm{~cm}^{-}\right.$ $\left.{ }^{1}\right)$ and $\mathrm{C}-\mathrm{H}$ stretching of alkane, and carboxylic acid $\left(2817.73-2966.12 \mathrm{~cm}^{-1}\right)$ and $\mathrm{C}-\mathrm{H}$ bending $\left(1311.20-1401.22 \mathrm{~cm}^{-1}\right)$, indicating the presence of alcohol, phenol, carboxylic group, ketones, ester, and ether in the samples. The presence of functional groups, namely hemicellulose, cellulose, pectin, and lignin compounds, indicates the potential of thickening and antioxidant agent in those fruit peels, and as adsorptive material (Desmukh et al., 2017). These results correlated with the findings of studies conducted by Pathak et al. (2017), Pathak et al. (2016), Pathak et al. (2015) and Gupta et al. (2015). It can be concluded that the biomass cell covers the existence of proteins and polysaccharides.

\section{Antioxidant Analysis}

Table 4 demonstrates the total phenolic content (TPC), extraction of the bound phenolic compound among the methanolic peel extract (Sommano et al, 2018A). The phenolic, RMP and UMP show high in TPC compared with other extracts. The result is in agreement with Siddiq (2017) who stated that the mango peel is rich in polyphenolic compound. The TPC of RBP and UBP is lower than RMP and UMP but higher than RPP and UPP. Afsharnezhad et al. (2017),
Romelle et al. (2016) and Baskar et al. (2011) stated that banana peel phenolic content is more than that of the pineapple but less than that of the mango peel, and thus supported this work. However, the TPC of banana peel was lower than pineapple peel. This is slightly dissimilar due to different extraction methods and cultivars of fruit species used (Deng et al., 2012). Compared with ripe and unripe conditions, the TPC of ripe fruits is higher than unripe fruits due to a different stage of ripening, caused by an increase in new biosynthesis of polyphenols as the fruit ripened (Ding \& Syazwani, 2016). Contrast with mango peels, TPC of UMP is higher than TPC of ripe mango peel because of the enrichment of polyphenolic compound in the UMP. The amount of this compound decreased as the mango fruit reached fully ripe maturity stage (Siddiq, 2017). Gallic acid and quercetin are such examples of phenolic compound and flavonoid compound present in mango peel and other fruit peel (Siddiq, 2017; Abdul Aziz et al., 2012). However, the TPC of fruit peels is dependent on the different solvent system and solvent polarity (Sultana et al., 2009).

The highest total flavonoid content (TFC) was from UMP $\left(37.60 \pm 0.00 \mathrm{mg}\right.$ of rutin. $\mathrm{g}^{-1}$ DW) and the lowest from UPP $(9.60 \pm 0.00 \mathrm{mg}$ of rutin. $\mathrm{g}^{-1} \mathrm{DW}$ ) as shown in Table 4 The TFC content of RBP and UBP does not have any difference. A similar finding was also reported by Afsharnezhad et al. (2017), Singh \& Immanuel, (2014) and Baskar et al. (2011) in which the banana peel had high flavonoid thus providing 
Table 4: Total phenolic, flavonoid, and scavenging activities through DPPH and FRAP assay of fruit peels

\begin{tabular}{ccccc}
\hline $\begin{array}{c}\text { Pectin } \\
\text { sources }\end{array}$ & $\begin{array}{c}\text { TPC }(\mathbf{m g} \text { of } \\
\left.\text { GAE.g }^{-1} \mathbf{D W}\right)\end{array}$ & $\begin{array}{c}\text { TFC }(\mathbf{m g ~ o f} \\
\left.\text { rutin.g }^{-1} \mathbf{D W}\right)\end{array}$ & $\begin{array}{c}\text { Degree inhibition of } \\
\text { DPPH }(\%)\end{array}$ & $\begin{array}{c}\text { FRAP }(\mathbf{m m o l} \\
\left.\text { FeSO }_{\mathbf{4}} \mathbf{.}^{-\mathbf{1}} \mathbf{D W}\right)\end{array}$ \\
\hline RBP & $4.88 \pm 0.01$ & $29.25 \pm 0.04$ & $84.53 \pm 0.22$ & $522.67 \pm 0.92$ \\
UBP & $4.31 \pm 0.02$ & $27.47 \pm 0.23$ & $79.94 \pm 0.24$ & $665.20 \pm 2.50$ \\
RPP & $4.95 \pm 0.02$ & $11.60 \pm 0.00$ & $82.20 \pm 0.22$ & $378.80 \pm 0.92$ \\
UPP & $2.75 \pm 0.01$ & $9.60 \pm 0.00$ & $77.54 \pm 0.00$ & $217.20 \pm 1.64$ \\
RMP & $5.50 \pm 0.00$ & $26.80 \pm 0.00$ & $89.83 \pm 0.00$ & $675.07 \pm 0.50$ \\
UMP & $5.90 \pm 0.00$ & $37.60 \pm 0.00$ & $81.07 \pm 0.12$ & $692.07 \pm 0.87$ \\
\hline
\end{tabular}

The data were reported in mean \pm standard deviation (SD).

high antioxidant activity, whilst the RPP is higher in TFC content compared to UPP. Afsharnezhad et al. (2017) stated that pineapple peel has high TFC like other peels. The value stated in that study is almost the same for UPP while it is slightly different in value for RMP. RMP and UMP have higher TPC and TFC compared to other fruit peels studied and this indicates its rich content of phenolics and flavonoids and exhibits good antioxidant activity (Umamahes et al., 2016; Hana et al., 2010). The result is in agreement with Siddiq (2017) and Abdul Aziz et al. (2012) who reported that mango is rich in phytochemical compound. UMP is slightly high in the TPC and TFC other than RMP. Hana et al. (2010) stated that mango peel contained more phenolic and flavonoid that is 3 to 6 folds higher than mango flesh. The result from this study shows the agreement with findings of previous studies that stated that both unripe and ripe MP had the highest potential as an antioxidant due to the content of TPC and TFC. Similar to TPC, the value of TFC increases during ripening due to new biosynthesis of polyphenols as the fruit ripens (Ding \& Syazwani, 2016). It is noted that, the differences between the present results of TPC, TFC, and other previous studies may be attributed to environmental condition, sample preparation and procedures, types of solvent, plant species and part of the fruit used.

UMP showed the highest percentage of DPPH $(89.83 \pm 0.00 \%)$ meanwhile UPP was the lowest DPPH $(77.54 \pm 0.00 \%)$. This result leads to the conclusion that the mango peel had a high degree of inhibition of DPPH than the two types of extract, showing strong scavenging activity toward the DPPH (Hana et al., 2010). The antioxidant activities of mango peel are due to synergistic actions of a bioactive compound present in the peel (Hana et al., 2010). The result obtained for RBP and UBP is in line with findings of Afsharnezhad et al. (2017) that the degree of inhibition of DPPH for banana peel was higher compared with pineapple peel. Besides, the extract from ripe fruits had a higher degree of inhibition compared to unripe fruits.

The percentage of FRAP was found to be the highest from UMP $\left(692.07 \pm 0.87 \mathrm{mmol} \mathrm{FeSO}_{4}\right.$. $\left.\mathrm{g}^{-1} \mathrm{DW}\right)$ and the lowest from UPP $(217.20 \pm 1.64$ mmol $\left.\mathrm{FeSO}_{4} \cdot \mathrm{g}^{-1} \mathrm{DW}\right)$. The highest reducing power for the ferric ion is due to the high content of flavonoids in the fruit peel (Afsharnezhad et al., 2017). Contrarily, RPP and UPP resulted in low TFC, hence the reducing power of both samples are low. Therefore, it is suggested that peel extract with low TFC, will simultaneously reduce the ability of the phytochemical in the extract to scavenge the ferric ions. To conclude, the high in scavenging activity of fruit peel is due to the high content of phytochemicals such as phenolic and flavonoids. Mango peel had higher scavenging activity towards DPPH and FRAP, assays followed by other fruit peels. What is inferred is that higher activity of DPPH may be attributed to the presence of high TPC and TFC as they played an important role as proton-donating ability and could serve as free radical inhibitors or scavengers, acting possibly as primary antioxidants (Morabbi Najafabad, \& Jamei, 2014). 


\section{Pectin Analysis}

Table 5 presents the comparison level of the equivalent weight of pectin from the peel of each fruit. The equivalent weight of pectin from the UBP and RBP is the highest compared to the equivalent weight of pectin from UPP, RPP, UMP and RMP. This could be described It can be said that UBP and RBP have good ability containing pectin, thus easily forming jelly than two those obtained from UPP, RP P, UMP, and RMP. This test indicates the thickening agent property of the samples. The results of the equivalent weights of pectin from RBP, UBP, RMP, and UMP have supported the report by Girma and Worku (2016), which found that the equivalent weight of pectin was $925.01 \mathrm{mg} / \mathrm{L}$ and $895.00 \mathrm{mg} / \mathrm{L}$ for banana and mango peels, respectively. Also, Sudhakar and Maini (2000) mentioned that pectin produced from mango peels has an equivalent weight of $727.00 \pm 6.00$ $\mathrm{mg} / \mathrm{L}$ and $971.00 \pm 4.00 \mathrm{mg} / \mathrm{L}$ with different extraction methods.

The equivalent weight of pectin from RPP and UPP showed the lowest values compared to other fruits studied, but it still has an ability to produce pectin and forming a gel. Additionally, the resulting equivalent weights of pectin were higher than those obtained from commercial pectin of citrus peels $(577.72 \pm 0.09 \mathrm{mg} / \mathrm{L})$ and apple pomace $(551.29 \pm 0.10 \mathrm{mg} / \mathrm{L})$. It has been proven that the pectin extracted from these fruit peels have the ability to form a gel due to the high amount of equivalent weight obtained. On the other hand, the ripe fruit peel produced a higher equivalent weight of pectin than unripe fruit peel. It could possibly be due to starch degradation happening through the ripening process, the galacturonic acid content increased with progressing ripeness. Galacturonic acid is the main important factor in pectin production. The high level of galacturonic acid is a requirement for satisfactory gelling properties, and most prominently to meet legal pectin specifications (Geerkens et al., 2015). Simply, along the ripeness process, the galacturonic acid will increase, thus producing more pectin. Hence, more pectin indicates more easily jelly will be formed. This result proved that the equivalent weight of pectin is dependant on the galacturonic acid amount, the ripe and unripe conditions of fruit and also the condition of the method of pectin extraction.

Degree of esterification (DE) determines the gelling nature of pectin which influences pectin application. The pectin extraction which is $>50 \%$ of DE is categorized as high methyl ester (HM) pectin while $<50 \%$ of DE is classified as slow methyl ester (LM) pectin (Joye \& Luzio, 2000). Pectin with a high DE is more viscous in solution. A RBP, UBP, RPP, UPP, RMP, and UMP pectin are categorized as high methoxyl pectin. The DE values were reported in a range from $59.59 \pm 0.89$ to 70.80 $\pm 0.95 \%$ (Table 5). The DE of RBP and UBP is consistent with the previous measurement of the range between 63.15 and $70.03 \%$, categorized as high methoxyl pectin (Khamsucharit et al., 2017). The UMP was produced high methoxyl pectin $(70.80 \pm 0.95 \%)$ than RMP was 70.26 $\pm 0.95 \%$. Degree of esterification decreases

Table 5: Chemical characterization of pectin from fruit peels

\begin{tabular}{ccccc}
\hline Pectin sources & $\begin{array}{c}\text { Equivalent weight (g/ } \\
\mathbf{m L})\end{array}$ & MeO (\%) & DE (\%) & AUA (\%) \\
\hline RBP & $955.65 \pm 28.16$ & $5.85 \pm 0.22$ & $64.33 \pm 0.64$ & $51.63 \pm 1.67$ \\
UBP & $920.73 \pm 25.66$ & $5.44 \pm 0.09$ & $61.75 \pm 1.09$ & $49.99 \pm 0.00$ \\
RPP & $851.37 \pm 11.75$ & $6.67 \pm 0.06$ & $64.67 \pm 0.14$ & $58.53 \pm 0.60$ \\
UPP & $781.76 \pm 24.44$ & $5.85 \pm 0.22$ & $59.59 \pm 0.89$ & $55.73 \pm 1.60$ \\
RMP & $867.46 \pm 23.18$ & $8.44 \pm 0.09$ & $70.26 \pm 0.27$ & $68.17 \pm 1.42$ \\
UMP & $829.08 \pm 20.83$ & $9.01 \pm 0.16$ & $70.80 \pm 0.95$ & $72.28 \pm 0.73$ \\
\hline
\end{tabular}

The data were reported in mean \pm standard deviation (SD). 
with increasing maturity (Sudhakar \& Maini, 1999). This DE content is slightly above the DE $\%$ of commercial citrus peel $(62.83 \pm 0.02$ $\%)$ and apple pomace pectins $(58.44 \pm 0.03 \%)$, indicating pectin of good quality suitable for commercial exploitation. The lower DE of RBP, UBP, RPP, and UPP compared to RMP and UMP might be ascribed to the alteration of pectins into protopectin which raises the sugars and makes the fruit softer (Bartley \& Knee, 1982) during maturation. DE actually is determined by on the stage of maturity, tissue, and species.

The methoxyl (MeO) content (Table 5) of the extracted pectin decreases within this range of $5.44-9.01 \%$. As known, the $\mathrm{MeO}$ content of commercial pectins generally varies from 8-11 $\%$ which can form high sugar gels with a high concentration of sugar $(>65 \%)$. whilst, the low $\mathrm{MeO}$ pectins content which is $<7.0 \%$ can form gels with a lower concentration of sugar. Based on the result, the RBP, UBP, RPP, and UPP indicates low $\mathrm{MeO}$ content $(<7 \%)$, thus able producing a gel with a low concentration of sugar. Due to their low-methoxy-containing pectins, it could be utilized as a gelling agent in the low-sugar-containing product (CastilloIsrael, 2015). The MeO content of RBP and UBP in this study differs with pectin extracted from banana type Kluai Nam Wa $(8.46 \pm 0.01$ $\%$ ), but slightly similar with banana type Kluai Khai (5.96 \pm 0.01$)$, Kluai Leb Mu Nang (4.31 $\pm 0.02)$ and Kluai Hom Thong (4.25 \pm 0.02$)$ (Khamsucharit et al., 2018). This shows that the $\mathrm{MeO}$ content of extracted pectin subjected to the mode of extraction and on the fruit source. For UMP and RMP, the MeO content indicates the pectin extracted capable of producing a good high-quality sugar level, which is in line with the findings of Girma \& Worku, 2016). Moreover, the $\mathrm{MeO}$ content from mango peels was slightly similar with $\mathrm{MeO}$ content from the commercial citrus peel $(9.06 \pm 0.03 \%)$ and apple pomace peel $(7.92 \pm 0.02 \%)$. Thus, highmethoxy - containing pectins of UMP and RMP could be utilized as a gelling agent in high-sugar - containing the product. Nevertheless, the $\mathrm{MeO}$ content of UMP is higher than RMP but differs from the $\mathrm{MeO}$ content from RBP, UBP, RPP, and UPP. It could be influenced by different fruit types, neutral sugar compositions, pectin content, molecular weight distribution and degree of methyl esterification changes during ripeness process (Ding et al., 2017).

Results in Table 5 are interpreted that the AUA content of RBP, UBP, RPP, and UPP are lower than $65 \%$, showing that the pectin content from these fruit peels has low purity and has impurities. A similar observation was found by Kamble et al. (2017). This impurity is due to the starch, protein, and sugar that precipitated together with the pectin during the extraction process (Azad et al., 2014). Further purification step is necessary to obtain good quality pectin. Moreover, these results were relatively similar to those previously reported for banana species; Saba (34.56 \%), Grande Naina (66.67 \%), Kluai Khai (36.46 \pm 0.02$)$, Kluai Leb Mu Nang $(66.67 \pm 0.02)$, Kluai Hom Thong $(37.49 \pm 0.01)$ and Kluai Hin $(934.56 \pm 0.01)$ banana peels (Castillo-Israel, 2015). However, the AUA content RMP and UMP is higher than $65 \%$. This value shows that the pectin from mango peels is pure and in a good range of pectin quality (from fruit considered in the range $68.5 \%$ to $75.0 \%$ ). This result was relatively similar with to those previously researched for mango peel by Sudhakar-and Maini (1999) with recovered pectin as $73.89 \pm 1.64 \%$ and $63.99 \pm 1.35 \%$ via different precipitation methods. It also looks like the AUA content found in commercial fruits such as apple pectin, apple pomace pectin and dragon fruit pectin which was 59.52 to $70.50 \%$ (Castillo-Israel, 2015).

\section{Conclusion}

The unripe banana peel (UBP), ripe banana peel (RBP), unripe pineapple peel (UPP), ripe pineapple peel (RPP), unripe mango peel (UMP) and ripe mango peel (RMP) were studied for the physicochemical characteristics which included physical properties, antioxidant analysis and pectin analysis for identifying their potential as an adsorbent, antioxidant and thickening agent potential. The results obtained showed that all fruit peels tend to show similarities in 
physical characteristics and are suitable to be used as adsorbent as the surface morphology indicated irregularity, rough and porosity surfaces. The proximate analysis supported a good performance of fruit peels as adsorbent. The FTIR result revealed that all fruit peels have high lignocelluloses material content. The RMP and UMP were enriched polyphenol compounds that showed high TPC, TFC, DPPH, and FRAP activity assay, thus revealing good potential as antioxidant agent compared to others. The pectin analysis revealed that the UBP and RBP have higher pectin than other peels and easily used for jelly formation. However, the degree of esterification result indicated all fruit peels have a good pectin content which can suitably be used as a thickening agent as well as for commercial exploitation. The $\mathrm{MeO}$ content resulted in lower percentage for RBP, UBP, RPP, and UPP but higher for UMP and RMP, thus classifying its suitability for a low-sugar and high-sugar containing products, respectively. On the other hand, the AUA content showed that RBP, UBP, RPP, and UPP have low purity of pectin than RMP and UMP. Therefore, this study indicated that each of fruit peel has its potential and performance to be as adsorbent, antioxidant and thickening agents. Therefore, these valuable findings could be taken into account for further investigation, to be considered as adsorbent in environmental research, or as antioxidant and thickening agent in food product development.

\section{Acknowledgements}

This research was partially funded by Universiti Tun Hussein Onn Malaysia (UTHM) for the TIER 1 grant (H077) as financial research support. The authors are also grateful to the management for providing adequate laboratory facilities in the execution of this study.

\section{References}

Abang Zaidel, D. N., Zainudin, N. N., Mohd Jusoh, Y. M., \& Muhamad, I. I. (2015). Extraction and Characterization of Pectin from Sweet Potato (Ipomoea Batatas)
Pulp. Journal of Engineering Science and Technology, 3(1), 22-29.

Abdul Aziz, N. A., Lee, M. W., Bhat, R., \& Lai, H. C. (2012). Evaluation of Processed Green and Ripe Mango peel and Pulp Flours (Mangfera indica var Chokonan) in terms of Chemical Composition, Antioxidant Compounds and Functional Properties. Journal of the Science of Food and Agriculture, 92,557-563.

Afsharnezhad, M., Shahangian, S. S., Panahi, E., \& Sariri, R. (2017). Evaluation of the Antioxidant Activity of Extracts from Some Fruit Peels. Caspian Journal of Environmental Sciences, 15(3), 213-222. doi:10.22124/cjes.2017.2463

Alaa El-Din, G., Amer, A. A., Malsh, G., Hussein, M. (2018). Review Study on the use of Banana Peels for Oil Spill Removal. Alexandria Eng. Journal, 57, 2061-2068. doi: http://dx.doi.org/10.1016/j. aej.2017.05.020

Anwar, J., Shafique, U., Waheeduz, Z., Salman, M., Dar, A., \& Anwar, S. (2010). Removal of $\mathrm{Pb}(\mathrm{II})$ and $\mathrm{Cd}(\mathrm{II})$ from Water by Adsorption on Peels of Banana. Bioresource Technology, 101(6), 1752-1755. doi. org/10.1016/j.biortech.2009.10.021

Aquino C. F., Salomão, L. C. C., Ribeiro, S. M. R., Lopes de Siqueira, D., Roberto P. (2015). Carbohydrates, phenolic compunds and antioxidant Antioxidant Activity in Pulp and Peel of 15 Banana, Rev. Bras. Frutic., 38, (4): (e-090). doi: 10.1590/010029452016090

Azad, K. M., Ali, M. A., Mst. Akter, S., Rahman, M. J., Ahmed, M. (2014). Isolation and Characterization of Pectin Extracted from Lemon Pomace during Ripening. Journal of Food and Nutrition Sciences. 2(2), 2014, 30-35. doi: 10.11648/j.jfns.20140202.12

Bartley, I. M., \& Knee, M. (1982). The Chemistry of Textural Changes in Fruit during Storage. Food Chemistry, 9(1), 47-58. doi:https:// doi.org/10.1016/0308-8146(82)90068-1 
Baskar, R., Shrisakthi, S., Sathyapriya, B., Shyampriya, R., Nithya, R., \& Poongodi, P. (2011). Antioxidant Potential of Peel Extracts of Banana Varieties (Musa sapientum). Food and Nutrition Sciences, 2, 1128-1133.

Castillo-Israel, K.A.T., Baguio, S.F., Diasanta, M.D.B., Lizardo, R.C.M., Dizon, E.I., Mejico, M.I.F. (2015). Extraction and characterization of pectin from Saba banana [Musa 'saba'(Musa acuminata x Musa balbisiana)] peel wastes: A preliminary study. Intern. Food Research Journal, 22(1), 202-207.

Chua L. S., Ismail, S. M., Chua K. H., Aminuddin, A., Azizah, A. (2018). Piper sarmentosum as an Antioxidant: A Systematic Review. Sains Malaysiana, 47(10), 2359-2368

Dai, H., \& Huang, H. (2016). Modified Pineapple Peel Cellulose Hydrogels Embedded with Sepia Ink for Effective Removal of Methylene Blue. Carbohydrate Polymers, 148, 1-10. doi:https://doi.org/10.1016/j. carbpol.2016.04.040

Deng, G., Shen, C., Xu, X., Kuang, R., Guo, Y., Zeng, L., Gao, L., Lin, X., Xie, J., Xia, E., Li, S., Wu, S., Chen, F., Ling, W., \& Li, H. (2012). Potential of Fruit Wastes as Natural Resources of Bioactive Compounds. International Journal of Molecular Sciences, 13, 8308-8323.

Department of Agriculture. (2016). Fruit Crops Statistic Malaysia. Putrajaya, Malaysia.

Deshmukh, P. D., Khadse, G. K., Shinde, V. M., \& Labhasetwar, P. (2017). Cadmium Removal from Aqueous Solutions Using Dried Banana Peels as an adsorbent: kinetic and equilibrium modeling. Journal of Bioremediation and Biodegradation, 8(3), 1-7.

Devi, R., Munjral, N., Gupta, A. K., \& Kaur, N. (2013). Effect of exogenous lead on growth and carbon metabolism of pea (Pisum sativum L) Seedlings. Physiology and molecular biology of plants. An
International Journal of Functional Plant Biology, 19(1), 81-89. doi:10.1007/s12298012-0143-5

Ding, P., \& Syazwani, S. (2016). Physicochemical Quality, Antioxidant Compounds and Activity Pineapple Fruit at Five Ripening Stages. International Food Research Journal, 23(2), 549-555.

Dotto, G. L., Sellaoui, L., Lima, E. C., \& Lamine, A. B. (2016). Physicochemical and Thermodynamic Investigation of $\mathrm{Ni}$ (II) Biosorption on Various Materials using the Statistical Physics Modeling. Journal of Molecular Liquids, 220, 129135. doi:https://doi.org/10.1016/j.molliq. 2016.04.075

Ekpete, O. A., Marcus, A. C., \& Osi, V. (2017). Preparation and Characterization of Activated Carbon Obtained from Plantain (Musa paradisiaca). Journal of Chemistry, $11,1-6$.

Geerkens, C. H., Nagel, A., Just, K. M., MillerRostek, P., Kammerer, D. R., Schweiggert, R. M., \& Carle, R. (2015). Mango Pectin Quality as Influenced by Cultivar, Ripeness, Peel Particle Size, Blanching, Drying, and Irradiation. Food Hydrocolloids, 51, 241251. doi:https://doi.org/10.1016/j.foodhyd. 2015.05.022

Girma, E., \& Worku, M. T. (2016). Extraction and Characterization of Pectin from Selected Fruit Peel Waste. International Journal of Scientific and Researched Publications, 6(2), 447-454.

Gupta, V. K., Nayak, A., \& Agarwal, S. (2015). Bioadsorbents for Remediation of Heavy Metals: Current Status and their Future Prospects. Environmental Engineering Research, 20(1), 1-18.

Hajar, N., Zainal, S., Nadzirah, K. Z., Roha, S. A. M., Atikah, O., \& Elida, T. T. Z. M. (2012). Physicochemical Properties Analysis of Three Indexes Pineapple (Ananas Comosus) peel extract variety N36. Asia-Pacific Chemical, Biological 
and Environmental Engineering Society Procedia, 4, 115-121.

Hana, K., Jeong, Y. M., Hyeonji, K., Dong, S. L., Moonjae, C., Hyung, K, C., Young, S. K., Mosaddik, A., \& Somi, K. C. (2010). Antioxidant and Antiproliferative Activities of Mango (Mangifera indica L.) Flesh and Peel. Food Chemistry, 121(2), 429-436.

Hossain, M. A., Hao Ngo, H., Guo, W. S., \& Nguyen, T. V. (2012). Removal of Copper from Water by Adsorption onto Banana Peel as Bioadsorbent. International Journal of Geomate, 2(4), 227-234.

Ibrahim, U. K., Kamarrudin, N., Suzihaque, M. U. H., \& Abd Hashib, S. (2017). Local Fruit Wastes as a Potential Source of Natural Antioxidant: An Overview. IOP Conference Series: Materials Science and Engineering, 206, 012040. doi:10.1088/1757$899 \mathrm{x} / 206 / 1 / 012040$

Jahurul, M. H. A., Zaidul, I. S. M., Ghafoor, K., Al-Juhaimi, F. Y., Nyam, K.-L., Norulaini, N. A. N., \& Mohd Omar, A. K. (2015). Mango (Mangifera indica L.) by-products and their valuable components: A review. Food Chemistry, 183, 173-180. doi:https:// doi.org/10.1016/j.foodchem.2015.03.046

Jawad, A. H., Mamat, N. F. H., Abdullah, M. F., \& Ismail, K. (2016). Adsoprtion of Methylene Blue onto Acid-treated Mango Peels: Kinetic, Equilibrium and Thermodynamic Study. Desalination and Water Treatment, 59, 210-219.

Joye, D., \& Luzio, G. A. (2000). Process for Selective Extraction of Pectins from Plant Material by Differential $\mathrm{pH}$. Carbohydrates Polymers, 43(4), 337-342.

Kamble, P.B., Gawande, S., \& Patil, T.S. (2017). Extraction of Pectin from Unripe Banana Peel. International Research Journal of Engineering and Technology, 4(7), 22592264. Retrieved from https://www.irjet. net/archives/V4/i7/IRJET-V4I7462.pdf

Khamsucharit, P., Laohaphatanalert, K., Gavinlertvatana, P., Sriroth, K., \&
Sangseethong, K. (2018). Characterization of Pectin Extracted from Banana Peels of Different Varieties. Food Science and Biothechnology, (27), 315-319.

Mandavgane, S., Pathak, P., \& Kulkarni, B. (2017). Fruit peel waste: Characterization and its Potential Uses.Current Science, 113(3), doi: 10.18520/cs/v113/i03/444-454.

Meda, A., Lamien, C. E., Romito, M., Milogo, J., \& Nacoulma, O. G. (2005). Determination of the Total Phenolic, Flavonoid and Proline Contents in Burkina Fasan Honey, as well as their Radical Scavenging Activity. Food Chemistry, 91, 571-577.

Morabbi Najafabad, A., \& Jamei, R. (2014). Free Radical Scavenging Capacity and Antioxidant Activity of Methanolic and Ethanolic Extracts of plum (Prunus domestica L.) in Both Fresh and Dried Samples. Avicenna journal of phytomedicine, 4(5), 343-353. Retrieved from https://www.ncbi.nlm.nih.gov/pubmed/ 25386397

Njoku, V. O., Foo, K. Y., Asif, M., \& Hameed, B. H. (2014). Preparation of Activated Carbons from Rambutan (Nephelium lappaceum) Peel by Microwave-induced $\mathrm{KOH}$ Activation for Acid Yellow 17 dye Adsorption. Chemical Engineering Journal, 250, 198-204. doi:https://doi.org/10.1016/j. cej.2014.03.115

Orozco, R. S., Hernàndez, P. B., Morales, G. R., Núñez, F. U., Villafuerte, J. O., Lugo, V. L., Ramirez, N. F., Diaz, C. E. B., \& Vàzquez, P. C. (2014). Characterization of Lignocellulosic Fruit Waste as an Alternative Feedstock for Bioethanol Production. Bioresources, 9(2), 1873-1885.

Pandit, S. G., Vijayanand, P., \& Kulkarni S.G. (2015). Pectic Principles of Mango Peel from Mango Processing Waste as Influenced by Microwave Energy. Food Scince and Technology, 64 (2), 1010-1014, doi:10.1016/j.lwt.2015.06.070

Pathak, P. D., Mandavgane, S. A., \& Kulkarni, 
B. D. (2017). Fruits Peel Waste: Characterization and its Potential Uses. Current Science, 13(3), 444- 454.

Pathak, P. D., Mandavgane, S. A., \& Kulkarni, B.D. (2016). Characterizing Fruit and Vegetable Peels as Bio Adsorbents. Current Science, 110(11), 2114-2124.

Plazzotta, S., Manzocco, L., \& Nicoli, M. C. (2017). Fruit and Vegetable Waste Management and the Challenge of Freshcut Salad. Trends in Food Science \& Technology, 63, 51-59. doi:https://doi. org/10.1016/j.tifs.2017.02.013

Romelle, F. D., Rani, A., \& Manohar, R. S. (2016). Chemical Composition of Some Selected Fruit Peels. European Journal of Food Science and Technology, 4(4), 12-21.

Rose, P. A. E., \& Abilasha, D. (2016). Extraction and Characterization of Pectin from Lemon Peel. International Journal of Advanced Science and Research, 1(12), 12-15.

Rosenkranz, M., Schnitzler, J. (April 2016) Plant Volatiles. In: eLS. John Wiley \& Sons, Ltd: Chichester. doi: 10.1002/9780470015902. a0000910.pub3

Shan Qin, Chin, N. L., Yusuf, Y. A. (2014). Extraction and Characterization of pectin from Passion Fruit Peels. Agriculture and Agricultural Science Procedia 2, 231 - 236.

Siddiq, M. (2017). Mango Fruit: Production Posthavest Science, Processing Technology and Nutrition. USA: John Wiley and Sons.

Singh, S., \& Immanuel, G. (2014). Extraction of Antioxidants from Fruit Peels and its
Utilization in Paneer. Journal of Food Processing and Technology, 5(7), 1-5.

Sommano, S. R., Ounamornmas, P., Nisoa, M., Sriwattana, S., Page, P., Colelli, G. (2018A). Characterisation and physiochemical properties of mango peel pectin extracted by conventional and phase control microwaveassisted extractions. Intern. Food Research Journal, 25(6), 2657-2665.

Sommano, S. R., Ounamornmas, P., Nisoa, M., Sriwattana, S. (2018B). Bioactive functionality of pectin from peels of seven Thai mango cultivars. Acta horticulturae. 423-428. doi: 10.17660/ ActaHortic.2018.12313.62

Sudhakar, D. V., \& Maini, S. B. (2000). Isolation and Characterization of Mango Peel Pectins. Journal of Food Processing and Preservation, 24(3), 209-227. doi:10.1111/j.1745-4549.2000.tb00414.x

Sultana, B., Anwar, F., \& Ashraf, M. (2009). Effect of Extraction Solvent/Technique on the Antioxidant Activity of Selected Medicinal Plant Extracts. Molecules, 14(6). doi:10.3390/molecules14062167

Umamahesh, K., Sivudu, S. N., \& Reddy, O. V. S. (2016). Evaluation of Antioxidant Activity, Total Phenolics and Total Flavonoids in Peels of Fve cultivars of Mango (Mangifera indica) Fruit. Journal of Medicinal Plants Studies, 4(2), 200-203.

Yoshiyuki, S., \& Yutaka, K. (2003). Pyrolysis of Plant, Animal and Human Waste: Physical and Chemical Characterization of the Pyrolytic Products. Bioresource Technology, 90, 241-247. 